Publisher: GSA

Journal: GEOL: Geology

Article ID: G35874

\title{
1Pacific plate deformation from horizontal thermal contraction
}

\section{Corné Kreemer ${ }^{1}$ and Richard G. Gordon ${ }^{2}$}

$3^{I}$ Nevada Bureau of Mines and Geology, and Seismological Laboratory, University of Nevada, 4Reno, 1664 N. Virginia Street, Reno, Nevada 89557-0178, USA

$5^{2}$ Department of Earth Science, Rice University, MS 126, 6100 Main Street, Houston, Texas

677005, USA

\section{ABSTRACT}

8 The central approximation of plate tectonics is that the plates are rigid, which gives the 9theory its rigor and predictive power. Space geodetic measurements are consistent with the 10rigidity of stable plate interiors, but some failures of plate-circuit closure, in particular of oceanic 11plates, indicate that plates may be measurably non-rigid. We explore the hypothesis that 12horizontal thermal contraction causes deformation of oceanic plates. Here we show significant 13expected displacement fields due to thermal contraction for the Pacific plate based on a 14previously proposed relationship between sea-floor age and strain rate and on two end-member 15assumptions on how strain compatibility is enforced. The predicted maximum $2.2 \mathrm{~mm} / \mathrm{yr}$ south16eastward motion of the north-eastern part of the plate relative to the Pacific-Antarctic Rise may 17contribute to a large part of the non-closure of the Pacific-North America plate motion circuit. 18Our predicted displacement rates cannot (yet) be confirmed by current space-geodetic data and 19will require seafloor geodesy with $1 \mathrm{~mm} / \mathrm{yr}$ accuracy. The spatial distribution of predicted 20moment rate agrees reasonably well with that of intraplate earthquakes epicenters, similar to 21 what is observed for plate boundary zones. Our results suggest that plate-scale horizontal thermal 22contraction is significant and that it may be partly released seismically.

\section{INTRODUCTION}


Publisher: GSA

Journal: GEOL: Geology

Article ID: G35874

24 Plate tectonics has transformed our view of how our planet works. The central

25assumption or approximation of plate tectonics is that the plates are rigid. The assumption of 26plate rigidity is what gives plate tectonics its rigor and predictive power. There are two main 27quantitative tests of plate rigidity: plate-circuit closure and space geodetic measurements. The 28hypothesis of plate rigidity has survived many critical tests (e.g., DeMets et al., 1990; Argus and 29Gordon, 1996; Dixon et al., 1996; Beavan et al., 2002).

30 Nonetheless, there is mounting evidence that tectonic plates, in particular oceanic plates, 31 are not rigid. For example, DeMets et al. (2010) find the largest misfit in the 3-plate circuit (i.e., 32inverting data only along the 3 mutual boundaries of those 3 plates) occurs for the Pacific-Nazca33Cocos circuit, namely $14 \pm 5 \mathrm{~mm} / \mathrm{yr}$ (95\% confidence limit). Another important circuit that fails 34closure is the 4-plate Pacific-Antarctica-Nubia-North America circuit (i.e., using data only along 35the Pacific-Antarctica boundary, the Antarctica-Nubia boundary, and the Nubia-North 36America boundary) used in plate reconstructions to estimate motion between the Pacific and 37North American plates. The sum of relative plate motions can be compared with geodetic 38estimates of Pacific-North America motion. This circuit fails closure with a misfit of $5 \pm 3$ 39mm/yr (DeMets et al., 2010).

40 There are several possible explanations for the non-closure of plate circuits; e.g., motion 41 of tectonic plates over the non-spherical Earth causes deformation of the plates (McKenzie, 421972; Turcotte, 1974). The explanation we explore here, however, is that some or all of the 43circuit misfits are caused by horizontal thermal contraction of the lithosphere. That such 44contraction occurs is assumed in the work of many who have studied the thermal evolution of the 45lithosphere and thermo-elastic stresses (e.g., Parmentier and Haxby, 1986; Sandwell and Fialko, 462004). The focus in most of these prior studies has been the difference in horizontal contraction 
Publisher: GSA

Journal: GEOL: Geology

Article ID: G35874

47between the upper and lower portions of the competent oceanic lithosphere (i.e., the lithosphere 48above the brittle-plastic transition (BPT)) and the bending moments applied to the lithosphere

49and the resulting flexure. Here we investigate the effect of vertically averaged horizontal thermal 50contraction in young oceanic lithosphere on plate-scale deformation by modeling the associated 51strain rate field. We focus on the Pacific plate.

\section{HORIZONTAL THERMAL CONTRACTION}

53 Kumar and Gordon (2009) presented the assumptions and methods used to determine the 54strain rate in cooling lithosphere due to thermal contraction. In one dimension, infinitesimal 55strain rate ${ }^{(\varepsilon())}$ due to a cooling rate $(\partial T / \partial t)$ is $=\alpha_{l}(\partial T / \partial t) \varepsilon$ where $T$ is temperature, $t$ is 56time, and ${ }^{\alpha_{l}}$ is the linear coefficient of thermal expansion, which has a value of $\approx 10^{-5} \mathrm{~K}^{-1}$. We 57assume that the horizontal contraction of oceanic lithosphere will be a response to thermal stress 58averaged from the surface of the lithosphere down to the base of the competent lithosphere. We 59assume that stresses are relaxed by solid-state flow below the BPT. Kumar and Gordon (2009) 60showed that the depth-averaged cooling rate for a column of competent lithosphere to equal $61 T_{m}\left[\exp \left(-A^{2}\right)-1\right] / 2 \mathrm{At} \overline{\sqrt{\pi}}$ where $A=\operatorname{erf}^{-1}\left(T_{l} / T_{m}\right), T_{l}$ is the temperature of the isotherm 62bounding the base of the competent lithosphere, and ${ }^{T} m$ is the initial temperature in a half-space 63cooling model (Turcotte and Oxburgh, 1967). Estimates of $T_{m}$ range from $1300{ }^{\circ} \mathrm{C}$ to $1350{ }^{\circ} \mathrm{C}$ 64(Hillier and Watts, 2005; McKenzie et al., 2005). Following Kumar and Gordon (2009), we 65choose the lower value for $T_{m}$ as is it leads to lower contraction rates than the alternative and 66thus we consider it to the be the more conservative option. McKenzie et al. (2005) and Wiens 67 and Stein (1983) showed that the limiting depth of earthquakes approximately follows $600{ }^{\circ} \mathrm{C}$. 68 Martinod and Molnar (1995) assumed the BPT to occur at a depth $\approx 20 \%$ greater than that of the 
Publisher: GSA

Journal: GEOL: Geology

Article ID: G35874

69limiting depth of earthquakes. We therefore set $T_{l}$ to $700^{\circ} \mathrm{C}$. This temperature also gives the

70best fit to the amplitude of geoid anomalies due to thermal stresses on profiles across fracture

71zones (Parmentier and Haxby, 1986). With the chosen values for $T_{l}, T_{m}$, and ${ }^{\alpha_{l}}$, we find

$72 \dot{\varepsilon} \approx-167.24 \cdot 10^{-5} / t$. We do not consider alternative cooling models as those differ only from

73the half-space cooling model for ages $>70 \mathrm{Ma}$ where the expected strain rates will be an order-

74of-magnitude lower than in the youngest lithosphere. We take $t=t^{\prime}+t_{0}$ with $t^{\prime}$ being the age of

75the lithosphere and $t_{0}$ being a parameter that accounts for the nonzero thickness of lithosphere

76along the axis of mid-ocean ridge segments. We assume $t_{0}$ equals $0.1 \mathrm{Ma}$, which corresponds to

77a zero-age lithospheric thickness of $\approx 2 \mathrm{~km}$ (Kumar and Gordon, 2009). Kumar and Gordon

78(2009) discussed the strain rates and displacement rates expected from horizontal thermal

79 contraction in a general way. Here we make explicit predictions for the Pacific plate.

\section{RESULTS}

81 We use the sea-floor age model (v. 3.6) of Müller et al. (1997) to estimate strain rates in

82grid cells $0.2^{\circ}$ by $0.25^{\circ}$ in longitude and latitude, respectively. Because of the ${ }^{1 / t}$ dependency of

83strain rate, we estimate the average age in each grid cell as the inverse average of the reciprocal

84age values in that cell. The total model of 197,343 cells spans the entire Pacific plate, with its

85boundaries defined by ridge-transform segments in the east and south (C. DeMets, pers. comm., 862010) and predominantly subduction zone trenches in the west and north (Bird, 2003). We set 87the age of areas with unknown age to $200 \mathrm{Ma}$.

88 We apply the method of Haines and Holt (1993) to determine a continuous model of

89 strain rates and associated velocities that best fits the expected age-based strain rate. For each 90grid cell the strain rates, and corresponding a priori covariance matrix, are set according to bi- 
Publisher: GSA

Journal: GEOL: Geology

Article ID: G35874

91axial, age-derived, shortening both parallel and perpendicular to the local age gradient. If we

92simply allowed the cells to shrink without enforcing strain compatibility, gaps would open up

93everywhere in our model with the largest gaps opening up in the youngest lithosphere. If we

94 forced all the gaps to close in young lithosphere, the result would be overlap in old lithosphere.

95Thus a sensible compromise is required for balancing extensional strains and contractional

96strains while enforcing strain compatibility along the boundaries of all the cells.

97 We consider two end-member cases in which the continuous model should best fit the

98expected strain rates. In Model 1, the a priori covariance matrix is set such that the modeled

99continuous area strain rate amplitudes best match the expected values for each grid cell, but the

100shortening rates parallel and perpendicular to the age gradient are not required to be equal. In

101Model 2, the a priori covariance matrix is set such that the model continuous tensor field best

102satisfies the expectation of isotropic shortening, but the area strain rates do not fit as well as in

103Model 1. In effect, the difference between the models is on how we set the a priori correlation

104between the two strain axes ( 0 for Model 1 and 1 for Model 2). The strain rates for Models 1 and

1052 are broadly similar but differ in detail (Fig. 1A and B, respectively). The deviations from the

106level of expected area strain rates and the isotropy of shortening are shown in the Electronic

107Supplement. For both models, the straining of the Pacific plate is dominated by horizontal

108thermal contraction but also include regions of extensional strain evidently required by strain

109compatibility and the other assumptions of our models (Figs. 1A and 1B). The regions of

110extension tend to be in older lithosphere and might be much smaller or disappear altogether if we

111assumed that lithospheric strength increased with age.

112 The associated velocity field results from the spatial integration of strain rates across the

113Pacific lithosphere. In young lithosphere the ridge-parallel component of the velocity field is 
Publisher: GSA

Journal: GEOL: Geology

Article ID: G35874

114potentially larger than the ridge-normal component, because there is more lithosphere with

115relatively large strain rate across which to integrate. The ridge-parallel component is, however,

116 controlled by offsets of ridge segments by transform faults, limiting the velocity. For Model 2 ,

117Figure 1C shows the velocity field in a reference frame that minimizes the predicted velocities at

118a set of GPS stations in old Pacific lithosphere and Figure 1D shows the velocity field in a

119reference frame that minimizes the velocities of points on the $0.78 \mathrm{Ma}$ isochron (Müller et al.,

1201997) along the Pacific-Antarctic Ridge. The velocity fields for Model 1 are shown in the GSA

121Data Repository and are fairly similar to those for Model 2. To test whether the thermal

122contraction can be observed geodetically, we also analyze data from available continuous GPS

123stations (see GSA Data Repository). Residual horizontal GPS velocities (after subtraction of a

124rigid-body rotation) are shown in Figure 1C.

\section{DISCUSSION}

126 Most GPS residual velocities differ insignificantly from zero at the $95 \%$ confidence level

127after we solve for and remove a rigid-body rotation (Fig. 1C). The reduced $\chi^{2}$ is 2.4 . We did

128not use the velocity for the stations at Guadalupe and Chatham Islands to calculate the rigid-body

129rotation. The station on Guadalupe Island is one of the few sites that has a considerable, but

130insignificant ( $95 \%$ C.L.), motion of $1.2 \pm 1.3 \mathrm{~mm} / \mathrm{yr}$ toward $\mathrm{S} 25^{\circ} \mathrm{E}$. Previous estimates for this

131station were larger and significant (Plattner et al., 2007; Argus et al., 2010). Either way, that

132station's motion cannot be explained by thermal contraction, which is $0.2-0.3 \mathrm{~mm} / \mathrm{yr}$ toward $\mathrm{SW}$

133at this location. For the area containing the Chatham Rise and Campbell Plateau, SE of New

134Zealand, our model predicts the largest velocities relative to the GPS locations on the old

135lithosphere. The $0.6 \mathrm{~mm} / \mathrm{yr}$ eastward and $0.6 \mathrm{~mm} / \mathrm{yr}$ southward motion for stations CHAT and

136CHTI on Chatham Island are roughly consistent with our predictions, but with only the former 
Publisher: GSA

Journal: GEOL: Geology

Article ID: G35874

137observation being significant. At Campbell Island (i.e., southwestern most Pacific island) we

138predict $1.3-1.7 \mathrm{~mm} / \mathrm{yr}$ to the $\mathrm{SE}$, inconsistent with a campaign velocity there of $3.7 \mathrm{~mm} / \mathrm{yr}$

139toward the NW (Beavan et al., 2002). If we transform that study's velocity field onto ours,

140however, the observed motion of Campbell Island becomes insignificant. A real test of whether

141our prediction is correct requires the installation of a CGPS station on Campbell Island (and

142other nearby islands) or seafloor geodesy with $1 \mathrm{~mm} / \mathrm{yr}$ accuracy.

143 We also present the predicted velocity field relative to the $0.78 \mathrm{Ma}$ isochron along the

144Pacific-Antarctic Ridge (Fig. 1D) to see how thermal contraction of the Pacific plate modifies

145the results found assuming plate rigidity in the Pacific-Antarctic-Nubia-North America plate

146motion circuit. In this approximate reference frame, places offshore Baja California move 1.7

147(Model 1) to 2.2 (Model 2) mm/yr toward the SE. The GPS station at Guadalupe Island could be 148used to test for that motion, but only if we had several GPS stations on the southernmost Pacific 149plate to provide a geodetic reference. Unfortunately, there are nearly no islands there. Although 150the up-to- $2.2 \mathrm{~mm} / \mathrm{yr}$ motion off western North America may help to explain the failure to close 151the Pacific-Antarctic-Nubia-North America circuit by $5 \pm 3 \mathrm{~mm} / \mathrm{yr}$ (DeMets et al., 2010), the 152thermal contraction in the Antarctic, Nubia, and North American plates needs to be modeled to 153address the problem fully. In any case, it is unlikely that thermal contraction can entirely explain 154a non-closure as large as the $14 \pm 5 \mathrm{~mm} / \mathrm{yr}$ observed for the Pacific-Nazca-Cocos circuit 155(DeMets et al., 2010), suggesting that additional deformation processes are involved in that 156three-plate circuit.

157 Is there other evidence that thermal contraction exists and controls the Pacific plate's 158intraplate strain rate field? To address this, we convert predicted strain rates to "tectonic" 159moment rates (which are proportional to strain rate times volume) and compare them with 
Publisher: GSA

Journal: GEOL: Geology

Article ID: G35874

160earthquake distributions. The number of events should be proportional to the tectonic moment

161rate if seismicity follows a Gutenberg-Richter distribution and the b-value and maximum

162expected moment are the same everywhere (e.g., Molnar, 1979). We use a catalog of 39

163intraplate events and explain the catalog in the GSA Data Repository.

164 We order our model grid cells from oldest to youngest age and count the cumulative

165number of events, until $5 \mathrm{Ma}$ (we exclude younger lithosphere to avoid possibly counting ridge-

166transform events as being intraplate). The normalized graph is shown in Figure 2A. The same

167 figure also shows for Model 1 and 2 the normalized cumulative moment rate $\left(M_{0}\right)$ for the same

168cell ordering. For the strain-to-moment conversion we assume that the seismogenic thickness

169 follows the $700^{\circ} \mathrm{C}$ isotherm. We also calculate the moment rates for alternative conversions in

170which the maximum seismogenic thickness is limited to $40 \mathrm{~km}$. Our results show that all curves

171have the same concave-up shape. A general decrease in seismicity with age was already

172observed by Wiens and Stein (1983) and the similarity in the curves suggest that horizontal

173thermal contraction provides a first-order control on this decrease. Because of the limited number

174of available earthquakes, it is not possible to prefer one particular moment rate model over

175another. From Figure 1A it is clear that there is a change in seismicity rate around $30 \mathrm{Ma}$. If a

176correlation between earthquake numbers and $M_{0}$ exists, we would expect it to be most obvious in

177the younger lithosphere. We therefore also show a similar comparison but only for ages between

1785 and $30 \mathrm{Ma}$ (Fig. 2B), which contains 21 events. For this case both cumulative earthquakes and

179predicted $M_{0}$ form a similar linear relationship with age.

180 The correlation we observe between tectonic moment rate and number of events has also

181 been found for most subduction zones and continental deformation zones (Kreemer et al., 2002;

182Kagan, 1999). These correlations do not, however, indicate the possibility that some, but not all, 
Publisher: GSA

Journal: GEOL: Geology

Article ID: G35874

183of the tectonic moment could be released aseismically. If all tectonic moment is released

184seismically, an unrealistically high maximum magnitude of $>9$ is needed to explain the

185earthquake rate and observed b-value (Okal and Sweet, 2007); thus most of the thermal strain

186rate in the Pacific is probably released aseismically. Moreover, it is expected that the moment 187release mainly reflects the differential rates of cooling with depth (Wessel, 1992) and not the 188vertically averaged cooling we consider here.

\section{CONCLUSIONS}

190 Strain rates from horizontal thermal contraction are much smaller than those occurring in 191narrow plate boundaries and generally below the level of direct detection with GPS 192measurements. When integrated across the plate away from the Pacific-Antarctic Ridge, 193however, velocities can become $2.2 \mathrm{~mm} / \mathrm{yr}$ off the coast of western North America and can 194contribute significantly toward observed non-closure of the Pacific-North America plate circuit. 195Moreover, the correlation between the distribution of earthquakes and predicted strain or 196moment rate supports that thermal strain rates are real and released seismically, at least partly. 197We conclude that horizontal thermal contraction should be considered in future development of 198the plate tectonic theory.

\section{ACKNOWLEDGMENTS}

200 We thank G. Blewitt for his help with the GPS data processing. This work was

201 supported by NSF grants OCE-0928969 (C.K) and OCE-0928961. (R.G.)

\section{REFERENCES CITED}

203Argus, D.F., and Gordon, R.G., 1996, Tests of the rigid-plate hypothesis and bounds on 204 intraplate deformation using geodetic data from very long baseline interferometry: Journal 
Publisher: GSA

Journal: GEOL: Geology

Article ID: G35874

205 of Geophysical Research. Solid Earth, v. 101, no. B6, p. 13555-13572,

206 doi:10.1029/95JB03775.

207Argus, D.F., Gordon, R.G., Heflin, M.B., Ma, C., Eanes, R.J., Willis, P., Peltier, W.R., and

208 Owen, S.E., 2010, The angular velocities of the plates and the velocity of Earth's centre

209 from space geodesy: Geophysical Journal International, v. 180, no. 3, p. 913-960,

210 doi:10.1111/j.1365-246X.2009.04463.x.

211Beavan, J., Tregoning, P., Bevis, M., Kato, T., and Meertens, C., 2002, Motion and rigidity of

212 the Pacific Plate and implications for plate boundary deformation: Journal of Geophysical

213 Research. Solid Earth. v. 107, no. B10, p. 2261, doi:10.1029/2001JB000282.

214Bird, P., 2003, An updated digital model of plate boundaries: Geochemistry Geophysics

215 Geosystems, v. 4, no. 3, doi:10.1029/2001GC000252.

216DeMets, C., Gordon, R.G., Argus, D.F., and Stein, S., 1990, Current plate motions: Geophysical

217 Journal International, v. 101, no. 2, p. 425-478, doi:10.1111/j.1365-246X.1990.tb06579.x.

218DeMets, C., Gordon, R.G., and Argus, D.F., 2010, Geologically current plate motions:

219 Geophysical Journal International, v. 181, no. 1, p. 1-80, doi:10.1111/j.1365-

220 246X.2009.04491.x.

221Dixon, T.H., Mao, A., and Stein, S., 1996, How rigid is the stable interior of the North American

222 Plate?: Geophysical Research Letters, v. 23, no. 21, p. 3035-3038, doi:10.1029/96GL02820.

223Engdahl, E.R., van der Hilst, R., and Buland, R., 1998, Global teleseismic earthquake relocation

224 with improved travel times and procedures for depth determination: Bulletin of the

225 Seismological Society of America, v. 88, no. 3, p. 722-743. 
Publisher: GSA

Journal: GEOL: Geology

Article ID: G35874

226Haines, A.J., and Holt, W.E., 1993, A procedure for obtaining the complete horizontal motions

227 within zones of distributed deformation from the inversion of strain rate data: Journal of

228 Geophysical Research, v. 98, no. B7, p. 12057-12082, doi:10.1029/93JB00892.

229Hillier, J.K., and Watts, A.B., 2005, Relationship between depth and age in the North Pacific

230 Ocean: Journal of Geophysical Research. Solid Earth. v. 110, no. B2, doi:

$231 \quad 10.1029 / 2004 J B 003406$.

232Kagan, Y.Y., 1999, Universality of the seismic moment-frequency relation: Pure and Applied

233 Geophysics, v. 155, no. 2-4, p. 537-573, doi:10.1007/s000240050277.

234Kreemer, C., Holt, W.E., and Haines, A.J., 2002, The global moment rate distribution within

235 plate boundary zones, in Stein, S., and Freymueller, J.T., eds., Plate Boundary Zones,

236 Geodynamics Series 30: Washington D.C., American Geophysical Union, p. 173-190.

237Kumar, R.R., and Gordon, R.G., 2009, Horizontal thermal contraction of oceanic lithosphere:

238 The ultimate limit to the rigid plate approximation: Journal of Geophysical Research. Solid

239 Earth. v. 114, no. B1, p. B01403, doi:10.1029/2007JB005473.

240Martinod, J., and Molnar, P., 1995, Lithospheric folding in the Indian Ocean and the rheology of

241 the oceanic plate: Bulletin de la Société Géologique de France, v. 166, no. 6, p. 813-821.

McKenzie, D.P., 1972, Plate tectonics, in Robertson, E.D. ed., The Nature of the Solid Earth, McGraw-Hill, New York, p. 323-360.

242McKenzie, D., Jackson, J., and Priestley, K., 2005, Thermal structure of oceanic and continental

243 lithosphere: Earth and Planetary Science Letters, v. 233, no. 3-4, p. 337-349,

244 doi:10.1016/j.epsl.2005.02.005.

245Molnar, P., 1979, Earthquake recurrence intervals and plate tectonics: Bulletin of the

246 Seismological Society of America, v. 69, no. 1, p. 115-133. 
Publisher: GSA

Journal: GEOL: Geology

Article ID: G35874

247Müller, R.D., Roest, W.R., Royer, J.-Y., Gahagan, L.M., and Sclater, J.G., 1997, Digital

248 isochrons of the world's ocean floor: Journal of Geophysical Research. Solid Earth. v. 102,

249 no. B2, p. 3211-3214, doi:10.1029/96JB01781.

250Okal, E.A., and Sweet, J.R., 2007, Frequency-size distributions for intraplate earthquakes in

251 Stein, S., and Mazzotti, S., eds., Continental Intraplate Earthquakes: Science, Hazard, and

252 Policy Issues: Geological Society of America Special Papers, v. 425, p. 59-71,

253 doi:10.1130/2007.2425(05).

254Parmentier, E.M., and Haxby, W.F., 1986, Thermal stresses in the oceanic lithosphere: Evidence

255 from geoid anomalies at fracture zones: Journal of Geophysical Research. Solid Earth. v. 91,

256 no. B7, p. 7193-7204, doi:10.1029/JB091iB07p07193.

257Plattner, C., Malservisi, R., Dixon, T.H., LaFemina, P., Sella, G.F., Fletcher, J., and Suarez-

258 Vidal, F., 2007, New constraints on relative motion between the Pacific Plate and Baja

259 California microplate (Mexico) from GPS measurements: Geophysical Journal International,

260 v. 170, no. 3, p. 1373-1380, doi:10.1111/j.1365-246X.2007.03494.x.

261Sandwell, D., and Fialko, Y., 2004, Warping and cracking of the Pacific plate by thermal

262 contraction: Journal of Geophysical Research, v. 109, no. B10, doi:10.1029/2004JB003091.

Turcotte, D.L., 1974, Membrane tectonics: Geophysical Journal of the Royal Astronomical Society, v. 36, p. 33-42.

263Turcotte, D.L., and Oxburgh, E.R., 1967, Finite amplitude convective cells and continental drift:

264 Journal of Fluid Mechanics, v. 28, no. 01, p. 29-42, doi:10.1017/S0022112067001880.

265Wessel, P., 1992, Thermal stresses and the bimodal distribution of elastic thickness estimates of

266 the oceanic lithosphere: Journal of Geophysical Research. Solid Earth. v. 97, no. B10,

267 p. 14177-14193, doi:10.1029/92JB01224. 
Publisher: GSA

Journal: GEOL: Geology

Article ID: G35874

268Wiens, D.A., and Stein, S., 1983, Age dependence of oceanic intraplate seismicity and

269 implications for lithospheric evolution: Journal of Geophysical Research. Solid Earth. v. 88,

270 no. B8, p. 6455-6468, doi:10.1029/JB088iB08p06455.

\section{FIGURE CAPTIONS}

272Figure 1. A) Contours of log second invariant of model strain rate tensor for Model 1 for which

273areal strain rates best match the expected values. Linear strain rates saturate at $10^{-11.5} \mathrm{yr}^{-1}$. White 274circles are epicenters of selected Pacific intraplate earthquakes from 1960 to 2008 (Engdahl et 275al., 1998) (see Electronic Supplement). Orthogonal bars indicate the orientations of principal 276strain rate directions with the lengths of the bars indicating the relative magnitudes of the two 277horizontal principal strain rates, black if contractional and white if extensional. B) same as A but 278for Model 2 for which the strain rates best satisfy isotropy. C) Residual GPS velocities (white 279 vectors), after removal of rigid-body rotation, with $95 \%$ confidence error ellipses. Black vectors 280and contours are predicted velocities from thermal contraction (Model 2) are shown in the same 281 frame as GPS, D) Predicted velocities (vectors and contours) from thermal contraction (Model 2) 282relative to the $0.78 \mathrm{Ma}$ isochron along the Pacific-Antarctic Ridge.

283Figure 2. A) Normalized cumulative number of earthquakes from oldest to youngest (i.e., $5 \mathrm{Ma}$ 284old) lithosphere. Also shown are normalized cumulative moment rate for both end-member

285models. Moment rate is defined as: $2 \mu V\left[\left(\dot{\varepsilon}_{x x}+\dot{\varepsilon}_{y y}\right) / 21+\sqrt{\left.\left(\dot{\varepsilon}_{x x}-\dot{\varepsilon}_{y y}\right) / 2\right]^{2}+\dot{\varepsilon}_{x y}^{\cdot 2}}\right]$, with the 286shear modulus, ${ }^{\mu}$, set to $30 \mathrm{GPa}$, and volume, $V$, is the area times a thickness set to the depth of 287 the $700^{\circ} \mathrm{C}$ isotherm (or is alternatively limited to be no more $40 \mathrm{~km}$.). B) same as A, but only for 288lithosphere between 5 and 30 Ma. old. 
Publisher: GSA

Journal: GEOL: Geology

Article ID: G35874

$289^{1}$ GSA Data Repository item 2014xxx, [Details on GPS data analysis and earthquake catalog], is 290available online at www.geosociety.org/pubs/ft2014.htm, or on request from

291editing@geosociety.org or Documents Secretary, GSA, P.O. Box 9140, Boulder, CO 80301, 292USA. 